\title{
Propriedades termofísicas da carne branca de frango: efeito da temperatura e do conteúdo de umidade
}

\author{
Thermophysical properties of white chicken meat: \\ effect of temperature and moisture content
}

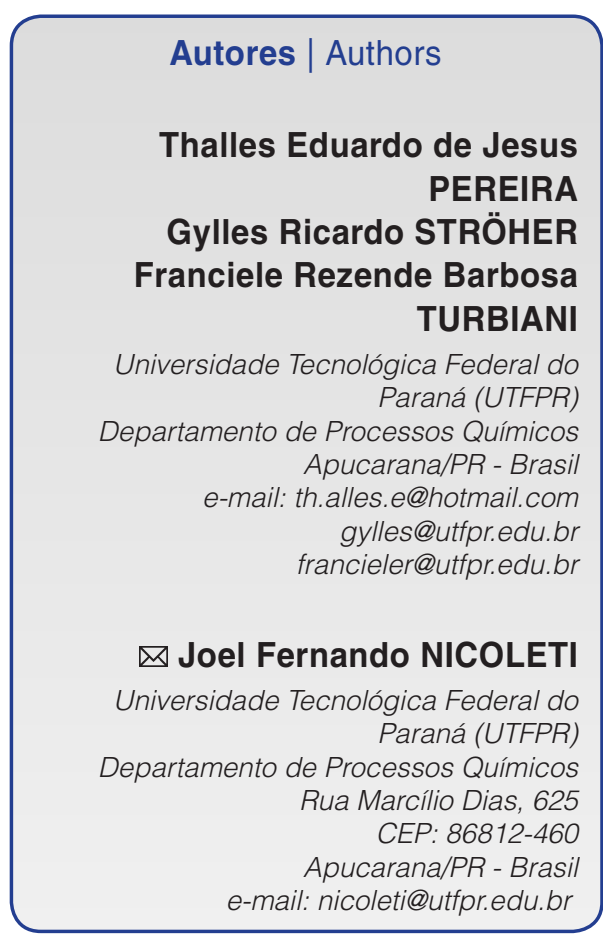

$\square$ Autor Correspondente / Corresponding Author

Recebido / Received: 11/10/2012 Aprovado / Approved: 14/11/2013 Publicado / Published: dez./2013

\section{Resumo}

O Estado do Paraná vem consolidando-se como o maior produtor e exportador da carne de frango no Brasil. As propriedades termofísicas, entre as quais a condutividade térmica, a difusividade térmica e a massa específica, são parâmetros importantes a ser considerados em projetos e operações que envolvam processamento térmico, como pasteurização, esterilização e cocção, e sistemas de refrigeração e congelamento. Neste contexto, o objetivo deste trabalho foi investigar estas propriedades termofísicas - condutividade térmica, difusividade térmica e massa específica - da carne do peito de frango, em função da umidade e da temperatura. A condutividade térmica foi avaliada pelo método da sonda linear com geração interna de calor; a difusividade térmica baseou-se no método de Dickerson, e a massa específica foi quantificada por picnometria. As três propriedades foram bastante afetadas pelo conteúdo de umidade, com um aumento nos valores da condutividade e difusividade térmica em teores de umidade mais altos, enquanto a massa específica teve um resultado inverso, com amostras mais densas à medida que o teor de umidade era reduzido. $\mathrm{O}$ efeito da temperatura conduziu a um aumento nos valores da difusividade e da condutividade térmica; porém, para a massa específica, de um modo geral, promoveu seu abaixamento.

Palavras-chave: Condutividade térmica; Difusividade térmica; Massa específica; Transferência de calor.

\section{Summary}

The state of Paraná has consolidated itself as the largest producer and exporter of poultry meat in Brazil. The thermophysical properties, including thermal conductivity, thermal diffusivity and specific mass are important parameters to be considered in projects and operations involving thermal processing such as pasteurization, sterilization, cooking, refrigeration and freezing. Thus the aim of this study was to investigate the thermophysical properties - thermal conductivity, thermal diffusivity and specific mass - of chicken breast meat as a function of moisture content and temperature. The thermal conductivity was measured by the linear probe method with internal generation of heat, thermal diffusivity was determined based on the method of Dickerson, while the density was measured by pycnometry. The three properties were strongly affected by moisture content, with an increase in the values of conductivity and thermal diffusivity at higher moisture contents, while the specific mass, or density, showed the opposite result, with denser samples at lower moisture contents. The effect of temperature led to an increase in the values for thermal diffusivity and thermal conductivity, but in general led to a lowering of the specific mass.

Key words: Thermal conductivity; Thermal diffusivity; Specific mass; Heat transfer. 


\section{Introdução}

A carne de frango vem ganhando a cada ano maior representatividade nas exportações brasileiras. Em 2008, o Estado do Paraná teve o seu melhor desempenho na história, fechando o ano com recorde de exportação e produção, e consolidando-se como o maior Estado produtor e exportador de frango de corte do Brasil (SINDIAVIPAR, 2009).

A carne de frango, além de saborosa, apresenta outros atrativos, como o alto valor nutricional e seu preço acessível. De acordo com USDA (2010), além de minerais, como $\mathrm{Ca}, \mathrm{Fe}, \mathrm{Mg}, \mathrm{P}, \mathrm{K}, \mathrm{Zn}, \mathrm{Mn}$ e Se, a carne é rica em vitaminas, em especial as do complexo $\mathrm{B}$, e apresenta os nove aminoácidos essenciais ao organismo (histidina, isoleucina, leucina, lisina, metionina, fenilalanina, treonina, triptofano e valina). O baixo teor de gordura da carne do peito de frango também é outro fator importante para aqueles que buscam uma dieta mais saudável.

Além do consumo convencional e caseiro, pelo processo de cocção da carne de frango, há uma diversidade de produtos industrializados à base desta carne. Entre estes, se destacam empanados, pastas ou patês de frango, embutidos fermentados e produtos reestruturados, como mortadela e salsichas (ROQUESPECHT, 1996). Os tratamentos térmicos, empregados de acordo com as tecnologias e suas peculiaridades distintas, requerem o emprego do calor e, em muitos casos, o subsequente resfriamento. A estimativa do calor total a ser adicionado ou removido, em cada processo ou etapa de processamento, está diretamente relacionada aos custos de energia de uma indústria do setor. O calor excessivo pode levar a uma redução da qualidade do produto final e onerar o processo desnecessariamente, enquanto que sua ineficiência pode acarretar produtos sensorialmente indesejáveis e falta de segurança alimentar.

As propriedades termofísicas de alimentos, entre as quais o calor específico, a condutividade térmica, a difusividade térmica e a densidade, são parâmetros relevantes na otimização de projetos e operações que envolvem processos térmicos, como pasteurização, esterilização e cocção, e sistemas de refrigeração e congelamento (KARUNAKAR et al., 1998). De acordo com Unklesbay et al. (1999), estas propriedades térmicas, além de serem essenciais na modelagem e na avaliação de operações de processamento de alimentos que envolvem transferência de calor, são especialmente importantes, quando os custos de energia, a qualidade e a segurança alimentar são considerados.

Marcotte et al. (2008) avaliaram a condutividade térmica, o calor específico, a difusividade térmica e a densidade de emulsões a partir de carnes e aves domésticas processadas (mortadela bolonhesa, linguiça italiana, peru, presunto e salsicha defumada). Como resultados, encontraram que a condutividade térmica aumentou linearmente com o aumento da temperatura entre 20 e $60{ }^{\circ} \mathrm{C}$, permanecendo constante, entre 60 e 80 ${ }^{\circ} \mathrm{C}$, para a maioria dos produtos, exceto para a mortadela bolonhesa. A densidade teve uma pequena queda em função da temperatura entre 20 e $40{ }^{\circ} \mathrm{C}$, seguida de um aumento até $60^{\circ} \mathrm{C}$, voltando a apresentar um decréscimo até a temperatura final de $80{ }^{\circ} \mathrm{C}$. Tanto a densidade quanto o calor específico foram fortemente influenciados pelo teor de carboidratos, enquanto a condutividade e a difusividade térmicas foram afetadas pelo conteúdo de sal.

Carne bovina magra, gordura e suas misturas, em proporções de 1:1, foram investigadas por Farag et al. (2008), na determinação das propriedades térmicas em função da temperatura, num alcance de -18 e $10^{\circ} \mathrm{C}$. Considerando-se a natureza das três matérias-primas, os valores de condutividade térmica, calor específico e difusividade térmica foram inferiores, conforme os teores de gordura eram aumentados, tendo sido avaliados numa mesma faixa de temperatura.

Embora alguns modelos matemáticos da literatura possam ser usados para a obtenção dos parâmetros termofísicos em função da composição de sistemas alimentícios e da temperatura (KARUNAKAR et al., 1998; GONZO, 2002; WANG et al., 2006; CARSON, 2006), há um consenso de que estes modelos não podem ser empregados indiscriminadamente, em razão dos desvios causado pela complexidade das matérias alimentícias (MARCOTTE et al., 2008).

Apesar de os valores das propriedades termofísicas da carne de frango poderem ser conseguidos por meio destas correlações empíricas, há uma carência de informações experimentais considerando a carne de frango nacional e dados mais atuais, o que contribui para a relevância desta investigação. Como justificativa adicional, está a expansão do setor industrial avícola do Estado do Paraná e sua contribuição econômica e social à região. Desta forma, o objetivo deste trabalho foi determinar experimentalmente as propriedades termofísicas - condutividade térmica, difusividade térmica e densidade - da carne do peito de frango, em função da umidade e da temperatura.

\section{Material e métodos}

As carnes do peito de frango, com pele e resfriadas, foram adquiridas da empresa Big Frango, situada no município de Rolândia, Paraná, Brasil. Após a separação da pele e do excesso de gordura, as carnes foram estocadas em freezer doméstico $\left(-18 \pm 2^{\circ} \mathrm{C}\right)$, para as análises posteriores.

Tanto para a quantificação da composição centesimal da carne do peito de frango quanto para ensaios 
experimentais na determinação de suas propriedades termofísicas, as carnes foram descongeladas em refrigerador $\left(1^{\circ} \mathrm{C}\right)$ por $48 \mathrm{~h}$, desossadas e, em seguida, trituradas em um moedor de carne (Marca Arbel, Modelo MTU 08).

A composição centesimal da carne do peito de frango foi avaliada em seis réplicas para o cálculo da média. O conteúdo de umidade foi determinado pelo método gravimétrico em estufa de circulação forçada (HORWITZ, 1997), a uma temperatura de $105^{\circ} \mathrm{C}$ por 3h; a quantificação do teor de lipídeos totais realizou-se de acordo com a técnica proposta por Bligh e Dyer (1959), empregando clorofórmio e metanol como solventes; a avaliação de proteínas foi feita pelo método de determinação de nitrogênio total kjeldahl (HORWITZ, 1997), pela transformação da matéria orgânica em sulfato de amônio em um digestor, seguindo para as etapas de neutralização com $\mathrm{NaOH}$ e destilação do nitrogênio, e, por fim, titulou-se o destilado com ácido clorídrico padronizado; as cinzas totais foram determinadas por incineração da amostra em forno mufla com temperatura programada em torno de $550^{\circ} \mathrm{C}$ por $4 \mathrm{~h}$ (HORWITZ, 1997) e o resultado foi obtido por diferença de massa antes e após incineração.

Para avaliar o efeito do teor de umidade sobre as propriedades termofísicas, a redução do conteúdo de umidade da carne do peito de frango moída foi conseguida com auxílio de uma estufa de circulação forçada (Marca Marconi, Modelo MA 033/216) a $60^{\circ} \mathrm{C}$, na qual as carnes foram dispostas sobre bandejas perfuradas de alumínio. Além da carne in natura reservada, em quatro tempos pré-programados, subsequentes parcelas de amostras eram retiradas do interior da estufa, totalizando, desta forma, cinco conteúdos de umidades distintos.

As medidas da condutividade térmica foram conseguidas pela metodologia da sonda linear em regime transiente, confeccionada com resistência elétrica níquel-cromo e termopar isolados eletricamente entre si, em seu interior (SAHIN e SUMMU, 2006). O aparato de cilindro de alumínio $(L=27,5 \mathrm{~cm}, D=5,30 \mathrm{~cm})$ utilizado nos experimentos foi previamente calibrado com água imobilizada, empregando carragena 1\% ( $p / p)$ (OLIVEIRA et al., 2005). As amostras, com distintos teores de umidade para cada ensaio, foram introduzidas no cilindro de alumínio e compactadas, para remoção de bolsas de ar. Em seguida, a sonda foi inserida em seu centro geométrico, contendo a amostra, sendo o conjunto (cilindro-amostra-sonda) devidamente vedado com tampão confeccionado de tecnil, para mergulhá-lo em um banho ultratermostatizado (Marca Marconi, Modelo MA-184) com água. Após a amostra entrar em equilíbrio com as temperaturas pré-programadas $\left(5-80^{\circ} \mathrm{C}\right)$ do banho, uma corrente elétrica ( $1 \mathrm{~A}$ ) foi gerada com auxílio de uma fonte de tensão controlada de $10 \mathrm{~V}$ e lida por um amperímetro, enquanto a temperatura era registrada a cada segundo por um registrador de dados Field Logger (Marca Novus).

O equacionamento para este sistema foi baseado na equação da conservação da energia em coordenadas cilíndricas, fluxo de calor radial, com geração interna de calor e condutividade térmica constante. De acordo com as condições de contorno apropriadas, obtém-se, como solução analítica, a Equação 1 (SAHIN e SUMMU, 2006).

$$
\mathrm{T}_{2}-\mathrm{T}_{1}=\frac{\dot{\mathrm{Q}}}{4 \mathrm{k} \pi} \ln \left(\frac{\mathrm{t}_{2}}{\mathrm{t}_{1}}\right)
$$

Com o valor da taxa de transferência de calor por metro linear da sonda térmica $(\dot{Q})$ calculado pela Equação 2 e, a partir dos pontos experimentais de temperatura ( $\mathrm{T}$ ) e tempo (t), avaliados na faixa linear compreendida entre os pontos inicial (subscrito 1) e final (subscrito 2), foi possível obter os valores de $k$ pelo coeficiente angular da Equação 1, obtido por uma regressão linear.

$$
\dot{\mathrm{Q}}=\frac{\mathrm{U} . \mathrm{i}}{\mathrm{I}}
$$

em que: $U$ = tensão (10 V); i = corrente elétrica (1 A); $\mathrm{I}$ = comprimento $(0,22 \mathrm{~m})$ do fio de resistência elétrica.

A difusividade térmica foi avaliada pelo método de Dickerson (1965), empregando um cilindro de bronze com as dimensões $R=15 \mathrm{~mm}$ e $\mathrm{L}=220 \mathrm{~mm}$, previamente calibrado com água imobilizada empregando carragena $1 \%(p / p)$ (OLIVEIRA et al., 2005). O cilindro foi preenchido com as amostras e termopares tipo $\mathrm{K}$ foram alocados em seu centro geométrico e na parede, para, em seguida, ser submerso em banho ultratermostatizado (Marca Marconi, Modelo MA-184). A elevação de temperatura do banho foi programada na faixa de 5 a $90{ }^{\circ} \mathrm{C}$, a uma taxa de 2 ${ }^{\circ} \mathrm{C} / \mathrm{min}$, e registrada a cada segundo por um registrador de dados Field Logger (Marca Novus).

O equacionamento foi baseado na equação da conservação da energia em coordenadas cilíndricas, regime transiente, fluxo de calor radial, sem geração interna de calor, condutividade térmica e taxa de elevação de temperatura constante $(\mathrm{dT} / \mathrm{dt}=\mathrm{A})$. De acordo com as condições de contorno apropriadas, tem-se como solução analítica a Equação 3:

$$
\left(T_{R}-T_{c}\right)=\frac{A}{4 \alpha} R^{2}
$$

em que: $R$ = raio do cilindro com temperatura correspondente a $T_{R} ; \mathrm{Tc}=$ temperatura do centro do cilindro; $A$ = taxa (dT/dt) de elevação de temperatura $\left({ }^{\circ} \mathrm{C} /\right.$ $\min ) ; \alpha=$ difusividade térmica. 
Com os valores de A, da diferença de temperaturas da parede e do centro do cilindro $\left(T_{B}-T_{C}\right)$ avaliados na faixa linear, e do raio do cilindro $(R)$, foi possível obter os valores da difusividade térmica $(\alpha)$ a partir da Equação 3, em função da temperatura média $\left[\left(T_{R}+T c\right) / 2\right]$.

A massa específica foi avaliada por picnometria (MOHSENIN, 1986), empregando água destilada como fluido picnométrico. A escolha deste fluido se deu por não ser reativo às amostras, ser não volátil, não ter ação de solvente, por não ser tóxicos e possuir densidade inferior à matéria-prima.

Os picnômetros foram previamente calibrados com água destilada à temperatura ambiente. A elevação de temperatura foi conseguida imergindo o picnômetro com as amostras em banho ultratermostatizado (Marca Marconi, Modelo MA-184), com varredura de temperatura entre 5 e $80^{\circ} \mathrm{C}$.

\section{Resultados e discussão}

Na avaliação da composição centesimal da carne do peito de frango avaliada neste trabalho, a média das seis réplicas apresentou 73,35 $\pm 1,68 \%$ de água, 20,33 $\pm 0,71 \%$ de proteínas, $2,65 \pm 0,46 \%$ de lipídeos, $1,09 \pm$ $0,10 \%$ de cinzas e, por diferença, 2,58\% de carboidratos, estando esses valores próximos ao encontrados em outros trabalhos. Torres et al. (2000) reportaram, para a carne do peito de frango, 73,81\% para umidade, 20,80\% para proteínas, 1,84\% para lipídeos e 1,10\% para cinzas. Conforme a Tabela Brasileira de Composição de Alimentos (UNICAMP, 2006), a carne do peito de frango contém $74,8 \%$ de água, $21,5 \%$ de proteínas, 3,0\% de lipídeos e 1,0\% de cinzas.

Considerando-se os valores da condutividade térmica da carne do peito de frango em função do conteúdo de umidade $(\times)$ e da temperatura da amostra, seu comportamento é ilustrado pela Figura 1. Optou-se por um ajuste linear aos pontos experimentais e suas respectivas equações e coeficientes de correlação (R), para uma umidade fixa, conforme são apresentados na Tabela 1.

Apesar de a temperatura influenciar o valor da condutividade térmica, percebe-se que o teor de umidade tem uma maior influência, observada pelos espaçamentos entre as retas, além de uma queda acentuada de seus valores em conteúdos de umidade menores.

De um modo geral, a faixa de valores da condutividade térmica, nos limites de temperatura e conteúdo de umidade avaliados, situou-se entre 0,10 e 0,50 W/m.K, observando-se uma clara tendência de a condutividade aumentar com a elevação da temperatura

Tabela 1. Equações lineares e respectivo $(R)$ obtidos pelos ajustes aos pontos experimentais da Figura 1

\begin{tabular}{ccc}
\hline X (b.s.) & Equação & $\mathbf{R}$ \\
\hline 2,80 & $\mathrm{~K}=0,472+8,14 \cdot 10^{-4} \cdot \mathrm{T}\left[\mathrm{T}\left({ }^{\circ} \mathrm{C}\right) ; \mathrm{k}(\mathrm{W} / \mathrm{m} \cdot \mathrm{K})\right]$ & 0,9552 \\
2,28 & $\mathrm{~K}=0,445+8,00 \cdot 10^{-4} \cdot \mathrm{T}\left[\mathrm{T}\left({ }^{\circ} \mathrm{C}\right) ; \mathrm{k}(\mathrm{W} / \mathrm{m} \cdot \mathrm{K})\right]$ & 0,9897 \\
1,66 & $\mathrm{~K}=0,318+1,05 \cdot 10^{-3} \cdot \mathrm{T}\left[\mathrm{T}\left({ }^{\circ} \mathrm{C}\right) ; \mathrm{k}(\mathrm{W} / \mathrm{m} \cdot \mathrm{K})\right]$ & 0,9965 \\
0,77 & $\mathrm{~K}=0,116+1,01 \cdot 10^{-3} \cdot \mathrm{T}\left[\mathrm{T}\left({ }^{\circ} \mathrm{C}\right) ; \mathrm{k}(\mathrm{W} / \mathrm{m} \cdot \mathrm{K})\right]$ & 0,9422 \\
0,49 & $\mathrm{~K}=0,093+3,20 \cdot 10^{-4} \cdot \mathrm{T}\left[\mathrm{T}\left({ }^{\circ} \mathrm{C}\right) ; \mathrm{k}(\mathrm{W} / \mathrm{m} \cdot \mathrm{K})\right]$ & 0,9287 \\
\hline
\end{tabular}

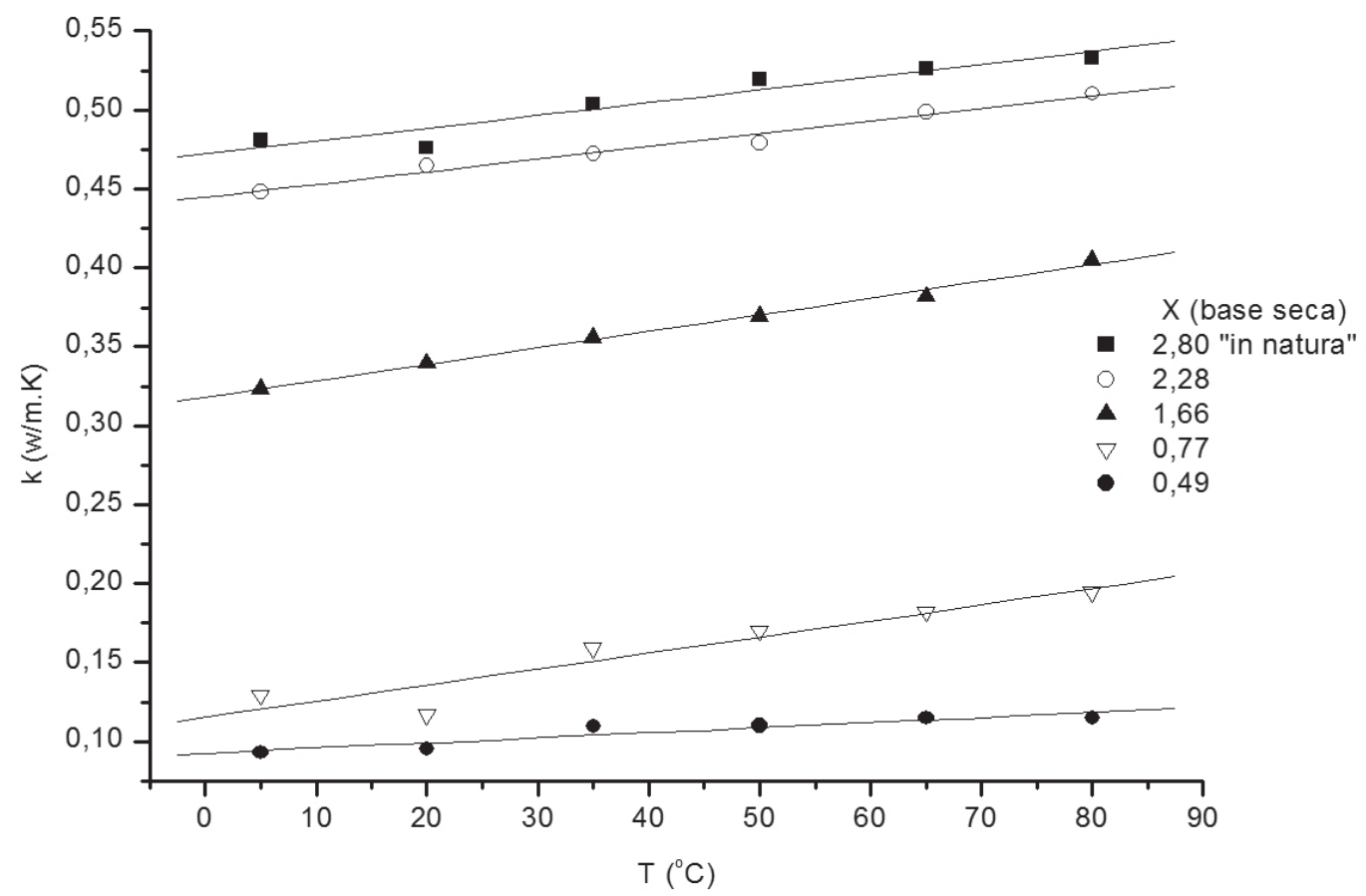

Figura 1. Condutividade térmica $(K)$ da carne do peito de frango em função da temperatura e do conteúdo de umidade $(X)$. 
(T) e com o aumento do conteúdo de umidade $(X)$. A condutividade térmica da água nas temperaturas de 5 ${ }^{\circ} \mathrm{C}$ e $80{ }^{\circ} \mathrm{C}$ é de, respectivamente, 0,582 e 0,671 W/m.K (MORAN et al., 2005); desta forma, é observado que o abaixamento do teor de umidade da amostra ocasiona uma redução no valor da condutividade térmica, fato este que mostra que, quanto mais 'diluído' for o material, mais o efeito da água em sua composição será pronunciado sobre este parâmetro. Seguindo esta colocação, pode-se entender que, conforme um material concentra, no caso, os constituintes restantes do alimento, seu efeito é reduzir o valor da condutividade térmica. Marcotte et al. (2008) encontraram, para a carne de peru, com conteúdo de umidade de $74,88 \%$, os valores da condutividade térmica entre 0,332 e 0,482 W/m.K, nas temperaturas de 22 e $79^{\circ} \mathrm{C}$, respectivamente.

Em relação aos resultados encontrados para os valores da difusividade térmica da carne do peito de frango, a Figura 2 ilustra o comportamento desta propriedade em função da temperatura média da amostra (T) e do conteúdo de umidade (X).

$\mathrm{O}$ alcance observado para a difusividade térmica avaliada em toda faixa de temperaturas e umidades consideradas ficou entre $0,95.10^{-7} \mathrm{~m}^{2} / \mathrm{s}$, em seu valor

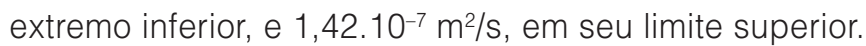

Para a carne do peito de frango fresca, com conteúdo de umidade de 72,7\%, é interessante observar que, nas temperaturas iniciais da medida da difusividade térmica, a carne do peito de frango está em torno de $1,25.10^{-7} \mathrm{~m}^{2} / \mathrm{s}$. Cengel (2004) reportou a difusividade térmica da carne de peito de frango a $0{ }^{\circ} \mathrm{C}$, num valor de $1,30.10^{-7} \mathrm{~m}^{2} / \mathrm{s}$, e nos experimentos de Huang e Liu (2009), o valor encontrado foi $1,524.10^{-7} \mathrm{~m}^{2} / \mathrm{s}$, mas estes autores não informam a temperatura do produto.

O efeito da umidade sobre a difusividade térmica da carne do peito de frango é bem nítido, observado por uma acentuada queda em seus valores em conteúdos de umidade baixos. A explicação acima, acerca da contribuição da água nos valores da condutividade térmica, também pode ser aplicada ao resultado encontrado para a difusividade térmica. Os valores da difusividade térmica da água nas temperaturas de $27 \mathrm{e}$ $77^{\circ} \mathrm{C}$ são, respectivamente, $1,46.10^{-7} \mathrm{~m}^{2} / \mathrm{s}$ e $1,55.10^{-7}$ $\mathrm{m}^{2} / \mathrm{s}$ (MORAN et al., 2005), e observa-se que, quanto mais úmido for um material, maior a parcela de contribuição da água sobre este parâmetro.

Em conteúdos de umidade altos, observa-se um aumento no valor da difusividade térmica com a elevação da temperatura até em torno de $55^{\circ} \mathrm{C}$, sendo que, a partir desta temperatura, ocorre uma redução desta grandeza. Entretanto, este efeito não é observado em amostras com conteúdo de umidade reduzido, em que ocorre um aumento da difusividade térmica em toda a faixa de temperatura avaliada. Esta queda nos valores da difusividade térmica das amostras com umidades altas talvez possa ser explicada pela exsudação da água contida no interior do alimento para suas extremidades, a qual arrasta a gordura já fundida pelo calor; forma-se, desta forma, uma camada isolante à transferência de calor, pois foi observado, nestas condições, que, ao

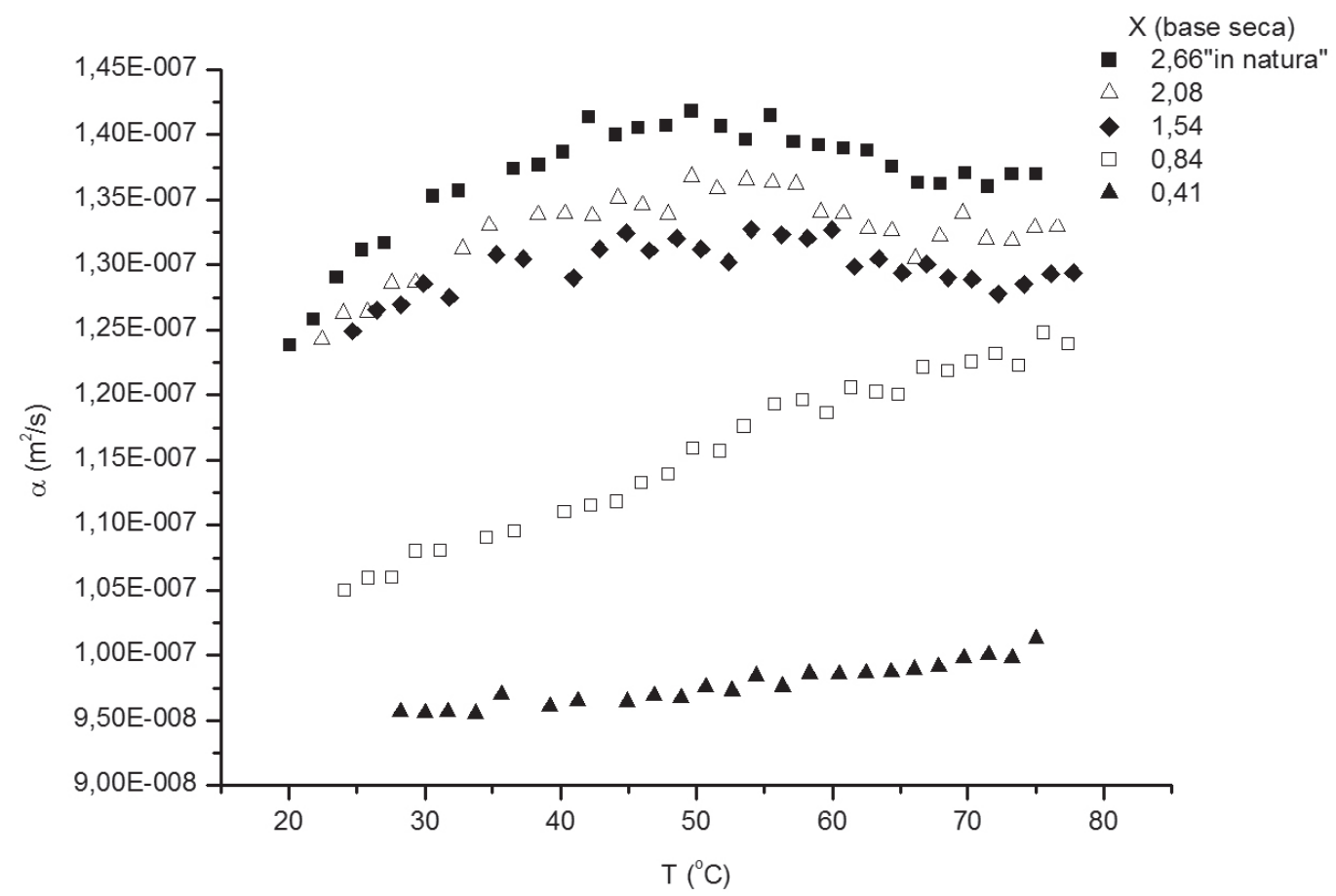

Figura 2. Difusividade térmica $(K)$ da carne do peito de frango em função da temperatura e do conteúdo de umidade (X). 


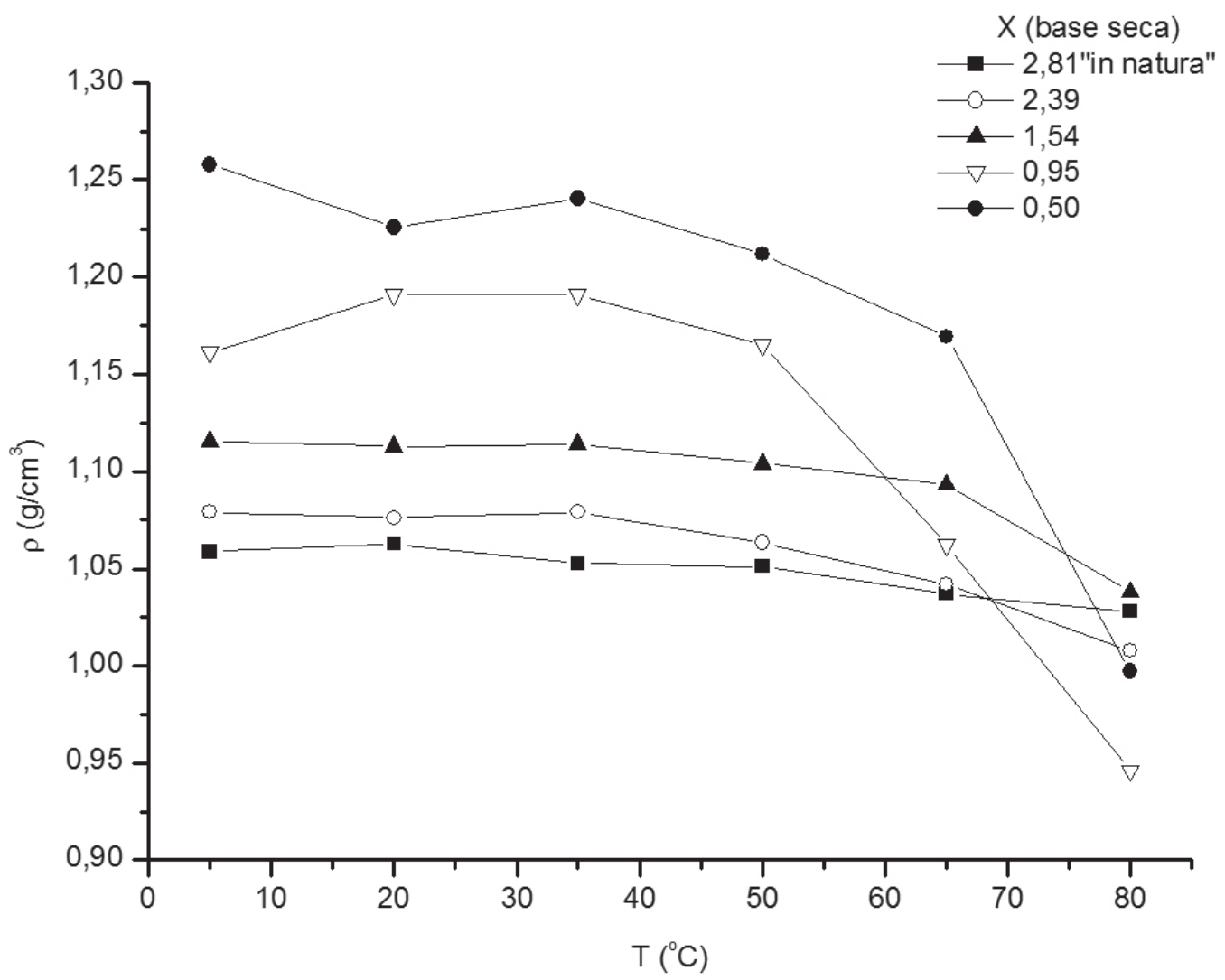

Figura 3. Massa específica $(P)$ da carne do peito de frango em função da temperatura e do conteúdo de umidade (X).

final do experimento, a quantidade de líquido contido no cilindro era expressiva, diminuindo, assim, o diâmetro da amostra no interior do cilindro. Nestas faixas, em que ocorre a diminuição dos valores da difusividade térmica com o aumento da temperatura, não podem ser bem aceitas e nem aplicadas, uma vez que a literatura aponta resultados inversos, colocando, desta forma, a validade deste método em questionamento para estas condições.

Os dados da massa específica da carne de frango em função da temperatura e do conteúdo de umidade (X) são apresentados na Figura 3. Há uma nítida tendência de os valores da massa específica aumentarem conforme o teor de umidade é reduzido; entretanto, em temperaturas mais altas, este efeito é menos pronunciado ou até mesmo contrário, pois se observa uma inversão entre as curvas. Pela Figura 3, ainda é possível observar que as amostras mais úmidas tiveram pouca variação em sua massa específica em função da temperatura, enquanto que, em umidades mais baixas, o efeito da temperatura é bastante acentuado.

Para a condição in natura das amostras da carne do peito de frango, em temperaturas até $35^{\circ} \mathrm{C}$, o valor da massa específica ficou próximo de $1,075 \mathrm{~g} / \mathrm{cm}^{3}$. Marcotte et al. (2008) encontraram que os valores da massa específica para diversos produtos à base de carne de aves domésticas ficaram na faixa entre 1,035 g/ $\mathrm{cm}^{3}$ e 1,055 $\mathrm{g} / \mathrm{cm}^{3}$, tomados em temperatura próxima de 22 ${ }^{\circ} \mathrm{C}$; entretanto, estes autores trabalharam com emulsões cárneas de produtos processados.

Marcotte et al. (2008) encontraram uma brusca redução nos valores da massa específica de produtos cárneos a partir de $60^{\circ} \mathrm{C}$. O mesmo comportamento foi verificado com a carne do peito de frango, porém, neste caso, esta queda pode ser notada em temperaturas superiores a $50^{\circ} \mathrm{C}$, em especial nas amostras com teores de umidade mais reduzidos. Segundo Marcotte et al. (2008), esta queda nos valores da densidade pode ocorrer possivelmente pela gelificação da proteína da carne, que provoca um pequeno aumento do volume da amostra.

\section{Conclusões}

As três propriedades termofísicas foram afetadas pelo conteúdo de umidade, com um aumento nos valores da condutividade e da difusividade térmicas, conforme o teor de umidade foi aumentado; por sua vez, a massa específica teve um resultado inverso, com amostras mais densas à medida que a quantidade de umidade era diminuída. A elevação da temperatura conduziu a um aumento nos valores da difusividade e da condutividade térmicas, porém, para a massa específica, de um modo geral, promoveu seu abaixamento. Observou-se um 
Propriedades termofísicas da carne branca de frango: efeito da temperatura e do conteúdo de umidade PEREIRA, T. E. J. et al.

comportamento não comum da difusividade térmica da carne do peito de frango com alto teor de umidade devido ao abaixamento em seus valores, em temperaturas superiores a $55^{\circ} \mathrm{C}$. Com os valores levantados destes parâmetros termofísicos, além de colaborar com o volume de informação, considerando a produção nacional, é possível contribuir com trabalhos futuros, que levem em consideração a solução numérica de equações baseadas na transferência de calor para a carne branca de frango.

\section{Agradecimentos}

Os autores agradecem ao CNPq (Proc. 473092/2009-3), pelo Auxílio Financeiro concedido, e à Fundação Araucária, pela Bolsa de Iniciação Científica (PIBIC 2010 e 2011).

\section{Referências}

BLIGH, E. G.; DYER, W. J. A rapid method of total lipid extraction and purification. Canadian Journal Biochemistry and Physiology, Ottawa, v. 37, n. 8, p. 911-917, 1959. http:// dx.doi.org/10.1139/059-099

CARSON, J. K. Review of effective thermal conductivity models for foods. International Journal of Refrigeration, Oxford, v. 29 , n. 6, p. 958-967, 2006. http://dx.doi.org/10.1016/j. ijrefrig.2006.03.016

CENGEL, Y. A. Heat Transfer - A Practical Approach. 3. ed. New York: McGraw-Hill, 2004. 908 p.

DICKERSON, R. W. An apparatus for measurement of thermal diffusivity of food. Food Technology, Chicago, v. 5, n. 19, p. 198-204, 1965.

FARAG, K. W.; LYNG, J. G.; MORGAN, D. J.; CRONIN, D. A. Dielectric and thermophysical properties of different beef meat blend over a temperature range of -18 to $+10^{\circ} \mathrm{C}$. Meat Science, Oxford, v. 79, n. 4, p. 740-747, 2008. PMid:22063038. http:// dx.doi.org/10.1016/j.meatsci.2007.11.005

GONZO, E. E. Estimating correlations for the effective thermal conductivity of granular materials. Chemical Engineering Journal, Oxford, v. 90, n. 9, p. 299-302, 2002. http://dx.doi. org/10.1016/S1385-8947(02)00121-3

HORWITZ, W. (Ed.). Official Methods of Analysis of the Association of Official Analytical Chemists. 16th ed. Washington: AOAC, 1997. 1141 p.

HUANG, L.; LIU, L. S. Simultaneous determination of thermal conductivity and thermal diffusivity of food and agricultural materials using a transiente plane-source method. Journal of Food Engineering, Oxford, v. 95, n. 1, p. 179-185, 2009. http:// dx.doi.org/10.1016/j.jfoodeng.2009.04.024

KARUNAKAR, B.; MISHRA, S. K.; BANDYOPADHYAY, S. Specific heat and thermal conductivity of shrimp meat. Journal of Food
Engineering, Oxford, v. 37, n. 3, p. 345-351, 1998. http://dx. doi. org/10.1016/S0260-8774(98)00071-5

MARCOTTE, M.; TAHÉRIAN, A. R.; KARIMI-ZINDASHTY, $Y$. Thermophysical properties of processed meat and poultry products. Journal of Food Engineering, Oxford, v. 88 , n. 3, p. 315-322, 2008. http://dx.doi.org/10.1016/j. jfoodeng.2008.02.016

MORAN, M. J.; SHAPIRO, H. N.; MUNSON, B. R.; DEWITT, D. P. Introdução à Engenharia de Sistemas Térmicos. São Paulo: Ed. LTC, 2005. 604 p.

MOHSENIN, N. N. Physical Properties of Plant and Animal Materials. New York: Gordon \& Breach Sci., 1986. 922 p.

OLIVEIRA, G. S.; TRIVELIN, M. O.; LOPES FILHO, J. F.; THOMEO, J. C. Thermo-physical properties of cooked ham. International Journal of Food Properties, Philadelphia, v. 8, n. 2, p. 387-394, 2005. http://dx.doi.org/10.1081/JFP-200059501

ROQUE-SPECHT, V. F. Aproveitamento de Resíduos de Carne de Frango. 1996. 84 f. Dissertação (Mestrado em Engenharia de Produção)-Universidade Federal de Santa Catarina, Florianópolis, 1996

SAHIN, S. S.; SUMMU, S. G. Physical Properties of Foods. New york: Ed. Springer, 2006. 257 p.

SINDICATO DAS INDÚSTRIAS DE PRODUTOS AVÍCOLAS DO ESTADO DO PARANÁ - SINDIAVIPAR. Revista Avicultura do Paraná, Curitiba, ano 2, n. 8, 2009.

TORRES, E. A. F. S.; CAMPOS, N. C.; DUARTE, M.; GARBELOTTI, M. L.; PHILIPPI, S. T.; MINAZZI-RODRIGUES, R. S. Composição centesimal e valor calórico de alimentos de origem animal. Ciência e Tecnologia de Alimentos, Campinas, v. 20, n. 2, p. 145-150, 2000. http://dx.doi.org/10.1590/S010120612000000200003

UNITED STATES DEPARTMENT OF AGRICULTURE - USDA. Agricultural Research Service. National Nutrient Database for Standard Reference Release 26. Disponível em: <http://www. nal.usda.gov/fnic/foodcomp/cgi-bin/list_nut_edit.pl>. Acesso em: 29 mar. 2010

UNIVERSIDADE ESTADUAL DE CAMPINAS - UNICAMP. Tabela Brasileira de Composição de Alimentos - TACO. 2. ed. Campinas: UNICAMP/NEPA, 2006. 113 p.

UNKLESBAY, N.; UNKLESBAY, K.; CLARKE, A. D. Thermal properties of restructured beef snack sticks throughout smokehouse processing. WLT-Food Science and Technology, Amsterdam, v. 32, n. 8, p. 527-534, 1999.

WANG, J. F.; CARSON, J. K.; NORTH, M. F.; CLELAND, D. J. A new approach to the modeling of the effective thermal conductivity of heterogeneous materials. International Journal of Heat and Mass Transfer, Oxford, v. 49, n. 17-18, p. 3075-3083, 2006. http://dx.doi.org/10.1016/j.ijheatmasstransfer.2006.02.007 